\title{
Corrigendum
}

\section{Agency, empowerment and culture}

\author{
Patti Tamara Lenard
}

Contemporary Political Theory (2010) 9, 140. doi:10.1057/cpt.2009.46

Correction to: Contemporary Political Theory (2009) 8, 455-465. doi:10.1057/cpt.2009.15

In the above review essay by Patti Lenard in Vol. 8, No. 4 of the journal, one of the reviewed books was erroneously referred to as 'Gender and Justice in Multicultural Communities' and also as 'Justice and Gender in Multicultural Societies'. The correct title of the book by Monique Deveaux is 'Gender and Justice in Multicultural Liberal States', published by Oxford University Press in 2006 and 2007. 